\title{
Anchoring of self-assembled plasmid DNA/ anti-DNA antibody/cationic lipid micelles on bisphosphonate-modified stent for cardiovascular gene delivery
}

\author{
This article was published in the following Dove Press journal: \\ International Journal of Nanomedicine \\ 9 March 2013 \\ Number of times this article has been viewed
}

\author{
Guilei Ma ${ }^{1, \#}$ \\ Yong Wangl,\# \\ Ilia Fishbein² \\ Mei Yu' \\ Linhua Zhang' \\ Ivan S Alferiev ${ }^{2}$ \\ Jing Yang' \\ Cunxian Song' \\ Robert J Levy ${ }^{2}$ \\ 'Institute of Biomedical Engineering, \\ Chinese Academy of Medical Sciences \\ and Peking Union Medical College, \\ Tianjin, People's Republic of China; \\ ${ }^{2}$ Children's Hospital of Philadelphia, \\ Abramson Research Building, \\ Philadelphia, PA, USA \\ \#These authors contributed equally \\ to this work
}

Correspondence: Cunxian Song Peking Union Medical College and Chinese Academy of Medical Sciences, Institute of Biomedical Engineering, 236 Baidi Road, Nankai District, Tianjin 300192,

People's Republic of China

Tel +86 2287892052

Fax +86228789 2052

Email songcx@bme.org.cn

Robert J Levy

Division of Cardiology, Children's Hospital of Philadelphia, Abramson

Pediatric Research Center, Room 702D,

3615 Civic Center Blvd, Philadelphia, PA

19104-4318, USA

$\mathrm{Tel}+2155906119$

$\mathrm{Fax}+2155905454$

Email levyr@email.chop.edu
Purpose: To investigate the anchoring of plasmid DNA/anti-DNA antibody/cationic lipid tri-complex (DAC micelles) onto bisphosphonate-modified $316 \mathrm{~L}$ coronary stents for cardiovascular site-specific gene delivery.

Methods: Stents were first modified with polyallylamine bisphosphonate (PAA-BP), thereby enabling the retention of a PAA-BP molecular monolayer that permits the anchoring (via vector-binding molecules) of DAC micelles. DAC micelles were then chemically linked onto the PAA-BP-modified stents by using N-succinimidyl-3-(2-pyridyldithiol)-propionate (SPDP) as a crosslinker. Rhodamine-labeled DNA was used to assess the anchoring of DAC micelles, and radioactive-labeled antibody was used to evaluate binding capacity and stability. DAC micelles (encoding green fluorescent protein) were tethered onto the PAA-BP-modified stents, which were assessed in cell culture. The presence of a PAA-BP molecular monolayer on the steel surface was confirmed by X-ray photoelectron spectroscopy and atomic force microscope analysis.

Results: The anchoring of DAC micelles was generally uniform and devoid of large-scale patches of defects. Isotopic quantification confirmed that the amount of antibody chemically linked on the stents was 17 -fold higher than that of the physical adsorbed control stents and its retention time was also significantly longer. In cell culture, numerous green fluorescent protein-positive cells were found on the PAA-BP modified stents, which demonstrated high localization and efficiency of gene delivery.

Conclusion: The DAC micelle-immobilized PAA-BP-modified stents were successful as a gene delivery system. Gene delivery using DAC micelle-tethered stent-based PAA-BP functionalization should be suitable for a wide array of single or multiple therapeutic gene strategies, and could be used on cardiovascular metallic implants for achieving efficient gene therapy.

Keywords: stent, polyallylamine bisphosphonate, plasmid DNA, micelles, gene delivery

\section{Introduction}

Cardiovascular gene delivery has been previously investigated for mitigation of in-stent restenosis. ${ }^{1-4}$ The use of the stent itself as a platform for gene delivery is attractive because it is site specific, potentially helping to avoid distal spread of therapeutic DNA and viral vectors. For example, a wide range of therapeutic DNA and viruses were delivered from the stent surface to reduce the extent of restenosis..$^{5-7}$ The above studies have all used polymer-coated stents to elute the genes. This polymer component, however, has been shown to cause local inflammatory responses and late thrombosis. ${ }^{8,9}$ The use of a technology that does not need a polymer layer may simplify the complex device 
coating formulation. For example, Fishbein et al has investigated alternatives to polymer coatings. ${ }^{10,11}$ They reported that pretreatment of metal alloy surfaces with an aqueous bisphosphonate solution, polyallylamine bisphosphonate (PAA-BP), enables adenoviral expressing inducible nitric oxide synthase vectors binding to bare metal, which showed effective gene vector delivery and resulted in significant inhibition of restenosis in vivo. Biocompatibility evaluation in rats also showed that there was no difference between PAA-BP-modified stents and control bare metal stents in the inflammatory response.

Since the late 1970s, it has been demonstrated that phosphonic acid, $\mathrm{RPO}_{3} \mathrm{H}_{2}$ ( $\mathrm{R}$ is an organic component), readily reacts with a wide range of metal salts and oxides, leading to a rich variety of one- to three-dimensional metal organic frameworks, also called metal phosphonates. The cohesion of these networks results from the formation of metal phosphonate ionocovalent bonds, which usually provide highly stable architectures. ${ }^{12,13}$ Moreover, phosphonic acids show a high compatibility with other organic functional groups and both their ester and acid forms can generally be used for surface modifications. In the study by Levy et al, PAA-BP that can both interact with metal oxide surfaces and provide reactive sites for chemical conjugation was synthesized by a direct Michael addition of PAA to the activated double bond of vinylidenebisphosphonic acid. The metallic surface could be modified through aminobisphosphonates exposure, thereby attaching to the metallic surface a derivatizable polybisphosphonate molecule that could, in turn, be covalently conjugated with vector-binding agents.

Gene delivery vectors such as naked plasmids, viral vectors, and nonviral nanodelivery have been successfully used in experimental gene therapy. ${ }^{14-16}$ However, there are several recurring issues that have led to reconsideration of their use in human clinical trials. These include inefficient in vivo gene transfer, high cytotoxicity, strong inflammatory reactions, and potential risk of viral DNA integration to host genome. Previous studies by the authors' group have reported a novel plasmid DNA vector composed of plasmid DNA/anti-DNA antibody/cationic lipid tri-complex (DAC micelles), which exhibits high transfection efficiency, high nuclear entry, and low toxicity both in vitro and in vivo. ${ }^{17,18}$ This complex formed stable nanoscaled micelles with a mean particle diameter around $360 \mathrm{~nm}$ and a zeta potential of $-15 \mathrm{mV}$ by self-assembling process. The authors' studies also showed that DAC micelles are structurally stable under cell culture conditions; furthermore, the entire complex can remain intact throughout cellular processing including nuclear entry.
The authors' group has focused on covalent linking of DAC micelles on the collagen-coated stents in order to deliver plasmid DNA by a vector tethering mechanism. ${ }^{19,20}$ This approach has been shown to be feasible, with high levels of regional expression in vitro and in vivo. In the current study, the intention was to explore new applications of DAC micelles in gene delivery and further investigate the binding stability and the controlled delivery behavior of DAC micelles bound on a PAA-BP-modified stent surface. First, the stent surface was modified with PAA-BP, thereby enabling the retention of a PAA-BP molecular monolayer that permits the attachment (via vector-binding molecules) of DAC gene vectors. After modification, the PAA-BP-modified stent surface was activated by N-succinimidyl-3-(2-pyridyldithiol)-propionate (SPDP). These thiol-reactive sites were then further reacted in each instance to attach DAC micelles for vector tethering. The novel plasmid DNA delivery system based on PAA-BP-modified stents was characterized by assessments of gene transfection efficiency.

\section{Materials and methods Materials}

316 L stainless steel foils were obtained from Goodfellow Corporation (Coraopolis, PA, USA). Mustang 316 L stainless steel coronary stents $(2.5 \times 13 \mathrm{~mm})$ were a gift from MicroPort Medical Co, Ltd (Shanghai, People's Republic of China). 316 L stainless steel foils were used for X-ray photoelectron spectroscopy (XPS) and atomic force microscopy (AFM) of the modified steel surface, while $316 \mathrm{~L}$ stainless steel stents were applied to in vitro gene expression. PAABP was a gift that Ivan S Alferiev synthesized. The plasmid encoding a green fluorescent protein (GFP) with enhanced fluorescence ( $p E G F P-N 3$ ) was purchased from Clontech Laboratories (Mountain View, CA, USA). Monoclonal mouse anti-bovine DNA antibody (immunoglobulin $\mathrm{M}$ ) recognizing double-strand and single-strand DNA (1 mg/mL) was obtained from US Biological (Swampscott, MA, USA) and nonspecific mouse immunoglobulin $\mathrm{M}$ antibody was from Rockland Immunochemicals Inc (Gilbertsville, PA, USA). Rat arterial smooth muscle cell (A10) was purchased from American Tissue Type Collection (Manassas, VA, USA). Lipofectamine $^{\mathrm{TM}} 2000$ was from Life Technologies (Carlsbad, CA, USA). SPDP was from Thermo Fisher Scientific (Rockford, IL, USA). Sodium iodide $\left(\mathrm{Na}^{125} \mathrm{I}\right)$ was from GE Healthcare (Little Chalfont, UK). GFP expression was assessed using fluorescent microscopy with a filter calibrated to detect fluorescein isothiocyanate (Eclipse E800; Nikon Corporation, Tokyo, Japan). 


\section{Metal surface modification with functional PAA-BPII}

To clean the stainless steel surface of any impurities, the $316 \mathrm{~L}$ stainless steel foils were rinsed twice in $1.5 \mathrm{~N}$ nitric acid (about 30 seconds each time), washed copiously with double distilled water, and incubated twice in isopropanol at $55^{\circ} \mathrm{C}$ with shaking ( 15 minutes each time). For stent cleaning/ surface activation, the additional steps of chloroform incubation ( 15 minutes, $55^{\circ} \mathrm{C}$, shaking) and heating (in a glass vial) at $250^{\circ} \mathrm{C}$ for 2 hours were taken. For PAA-BP modification, the cleaned metal samples were exposed to $3 \%(\mathrm{w} / \mathrm{v})$ aqueous PAA-BP (pH 5.5) at $60^{\circ} \mathrm{C}$ for 4 hours. Upon completion of incubation with PAA-BP, each sample was rinsed with an excess amount of double distilled water.

\section{Surface characterization}

The surface elemental composition was analyzed by XPS ESCALABMk II (VG Scienta, Uppsala, Sweden) equipped with an aluminum $\mathrm{K} \alpha \mathrm{X}$-ray source. Surface profiles were visualized by using a Dimension ${ }^{\text {TM }} 3100$ AFM (Veeco Instruments, Santa Barbara, CA, USA). Imaging was performed in the intermittent noncontact (tapping) mode by using oscillating linear silicon tips with a resonance frequency range of 300-350 Hz. Each data scan was collected over a $25 \mu \mathrm{m}^{2}$ area at a scanning frequency of $0.50 \mathrm{~Hz}$.

\section{Protocol for preparing DAC micelle- tethered PAA-BP-modified stents}

The PAA-BP-modified stents were reacted with SPDP $(20 \mathrm{mg} / \mathrm{mL})$ at room temperature for 2 hours followed with dithiothreitol to introduce sulfhydryl groups on the stents. Separately, the mouse monoclonal anti-DNA antibody was reacted with an excess of SPDP to introduce dithiol groups on the antibody molecules. The dithiol-activated anti-DNA antibody was then chemically linked to the stents through the thiol exchange reaction. The antibody-bound stent was then incubated in a $p E G F P-N 3$ DNA solution $(20 \mu \mathrm{g}$ pure plasmid DNA in $200 \mu \mathrm{L}$ Dulbecco's modified Eagle's medium [DMEM]) at $37^{\circ} \mathrm{C}$ for 1 hour followed by an extensive rinse with copious phosphate buffered saline (PBS) solution. The stents were further reacted with Lipofectamine 2000 reagent $(5 \mu \mathrm{L} / 200 \mu \mathrm{L})$ and incubated at room temperature for 30 minutes before incubation with cells. A nonspecific antibody was attached to the modified stents in the same manner as the contrast. In some cases, physical absorption of the antibody onto PAA-BP-modified stents was performed and used as the control.
Rhodamine-labeled DNA was used to assess the anchoring of DAC micelles on PAA-BP-modified stents under a fluorescence microscope (Nikon Eclipse E800).

\section{Binding capacity and stability of ${ }^{125}$-labeled anti-DNA antibody on PAA-BP-modified stents}

Anti-DNA antibody was iodinated by a modified chloramine-T procedure..$^{21}$ A $250 \mu \mathrm{g}$ aliquot of anti-DNA antibody $(2.2 \mathrm{mg} / \mathrm{mL})$ was mixed with $3.5 \mu \mathrm{L} \mathrm{Na}{ }^{125} \mathrm{I}(37 \mathrm{MBq})$ and $60 \mu \mathrm{L}$ chloramine- $\mathrm{T}(5 \mathrm{mg} / \mathrm{mL}, \mathrm{pH} 7.5)$ at room temperature and incubated for 3 minutes. The reaction was stopped by adding $80 \mu \mathrm{L}$ of a sodium metabisulfite solution $(10 \mathrm{mg} / \mathrm{mL}$, pH7.5). ${ }^{125}$ I-labeled antibody was purified by gel filtration on a Sephadex ${ }^{\circledR}$ G-50 column (Sigma-Aldrich, St Louis, MO, USA) to remove unreacted iodine. The ${ }^{125} \mathrm{I}$-labeled antibody was activated with SPDP and chemically linked on the stents as described above $(n=5)$. A control group was made by directly soaking the PAA-BP-modified stents in the ${ }^{125}$ I-labeled antibody solution $(n=5)$. Both types of antibody-loaded stents were subjected to the same PBS rinse procedure. To remove the unbound antibody, the eluting solution was monitored using a gamma counter until the level of radioactivity was close to the background. The binding capacity of the antibody on the stents was determined by measuring the radioactivity remaining on the stents. To evaluate the binding stability of the ${ }^{125}$ I-labeled antibody, stents were incubated in PBS at $37^{\circ} \mathrm{C}$ with shaking (140 rpm). At predetermined time intervals, the incubation solution was replaced with the same volume of fresh PBS and the radioactivity remaining on the stents was measured with a gamma counter.

\section{Cell transfection by DAC micelle- tethered stents in vitro}

The stents were incubated in a $1 \times 10^{6} \mathrm{~A} 10$ cell (rat arterial smooth muscle cells) suspension at $37^{\circ} \mathrm{C}$ for 1 hour before being placed into $35 \mathrm{~mm}$ cell culture plates. A suspension of $1 \times 10^{5}$ A10 cells in DMEM was added. The cells were incubated in serum-free medium for 5 hours followed by the addition of fetal bovine serum to a final concentration of $5 \%$. The culture medium was changed to growth medium (DMEM $+10 \%$ fetal bovine serum $+1 \%$ penicillin/streptomycin) after 24 hours. The $p E G F P-N 3$ gene expression, as demonstrated by fluorescein isothiocyanate-positive cells, was observed on a Nikon Eclipse E800 fluorescent microscope (Nikon Eclipse E800) equipped with SPOT version 3.02 software (SPOT Imaging 
Solutions, Sterling Heights, MI, USA) and photographs were taken after 3 days of cell culture.

\section{Statistical analysis}

Data for all experiments were expressed as the mean \pm standard error of the mean. The significance of differences was assessed using Student's $t$-test or analysis of variance. $P<0.05$ was considered statistically significant.

\section{Results and discussion}

\section{Chemical reasoning of tethering} DAC micelles onto the PAA-BPmodified metal surface

In this study, the 316 L stainless steel substrates - mainly composed of iron, chromium, and nickel - were modified through PAA-BP exposure, thereby attaching to the metallic surface a derivatizable polybisphosphonate molecule that could, in turn, be covalently conjugated with DAC micelles for local gene delivery. A heterobifunctional crosslinker, SPDP, was used to chemically link the DAC micelles on the metal stent via a PAA-BP monolayer that provided the reactive amine groups. The basic chemistry for DAC micelles for binding on PAA-BP-modified stent surface is: (1) to introduce sulfhydryl functional groups on the PAA-BP monolayer; (2) to derivatize the anti-DNA antibody with pyridyl disulfides; (3) to couple the dithiol antibody to the sulfhydryl-activated PAA-BP monolayer; and (4) to form stable DAC micelles with incubation with plasmid DNA and cationic lipid. Thus, DAC micelles were covalently linked on the PAA-BP-modified stents.

\section{Surface characterization of a functional PAA-BP-modified metal surface}

XPS analysis was undertaken to verify the surface modification with PAA-BP. XPS confirmed the presence of a PAA-BP

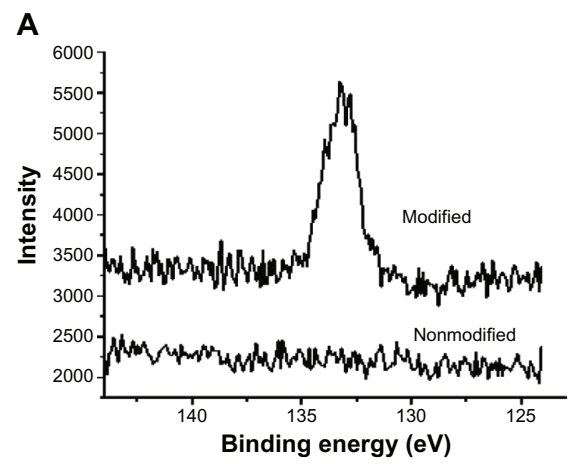

molecular monolayer on the steel surface, demonstrating the emergence of a characteristic phosphorus $2 p$ signal in the XPS of the treated sample; a phosphorus signal is not present in the control $316 \mathrm{~L}$ steel (Figure 1A). Furthermore, the characteristic iron $2 p$ peaks of the steel substrate were still present in the XPS from the PAA-BP-modified sample (Figure 1B), indicating that the thickness of the PAA-BP coordination layer is less than the effective XPS sampling depth $(5 \mathrm{~nm})$.

AFM was used to visualize surface topography after PAA-BP modification. AFM images of the surface of the bare and PAA-BP-modified metal surface are shown in Figure 2. AFM images show that the PAA-BP-modified metal surface displayed substantially increased roughness (root mean square: $25 \pm 5 \mathrm{~nm}$, measured on $2 \mu \mathrm{m} \times 2 \mu \mathrm{m}$ region), compared with that of bare surface (11 $\pm 3 \mathrm{~nm})$. After PAA-BP modification, the surface morphology changed tremendously. The increase of local surface roughness following PAA-BP modification illustrates that topographical as well as chemical changes to the metal surface can occur as a result of surface modification. It is likely that a thin, rough, but stable PAA-BP monolayer was formed on the metal surface.

\section{Binding capacity and stability of ${ }^{125}$-labeled anti-DNA antibody on PAA-BP-modified stents}

The anti-DNA antibody was successfully labeled with radioisotope ${ }^{125} \mathrm{I}$. Unreacted ${ }^{125} \mathrm{I}$ was completely separated from the ${ }^{125} \mathrm{I}$-labeled antibodies ( ${ }^{125} \mathrm{I}$-antibody) by gel filtration on a Sephadex G-50 column. The radiochemical purity reached a level of $98 \%$, as determined by paper chromatography. The final concentration of the dithiol derivative ${ }^{125} \mathrm{I}$-antibody (after SPDP activation) was approximately $60 \mu \mathrm{g} / \mathrm{mL}$,

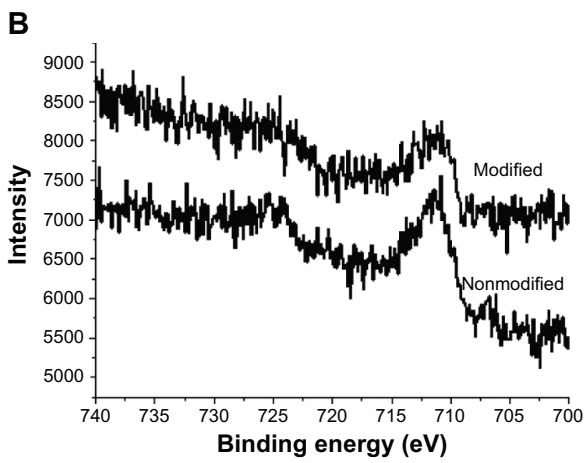

Figure I X-ray photoelectron spectroscopy to detect (A) phosphorus and (B) iron on nonmodified and polyallylamine bisphosphonate-modified steel surfaces demonstrates the appearance of phosphorus after polyallylamine bisphosphonate treatment with persistent iron signals. 

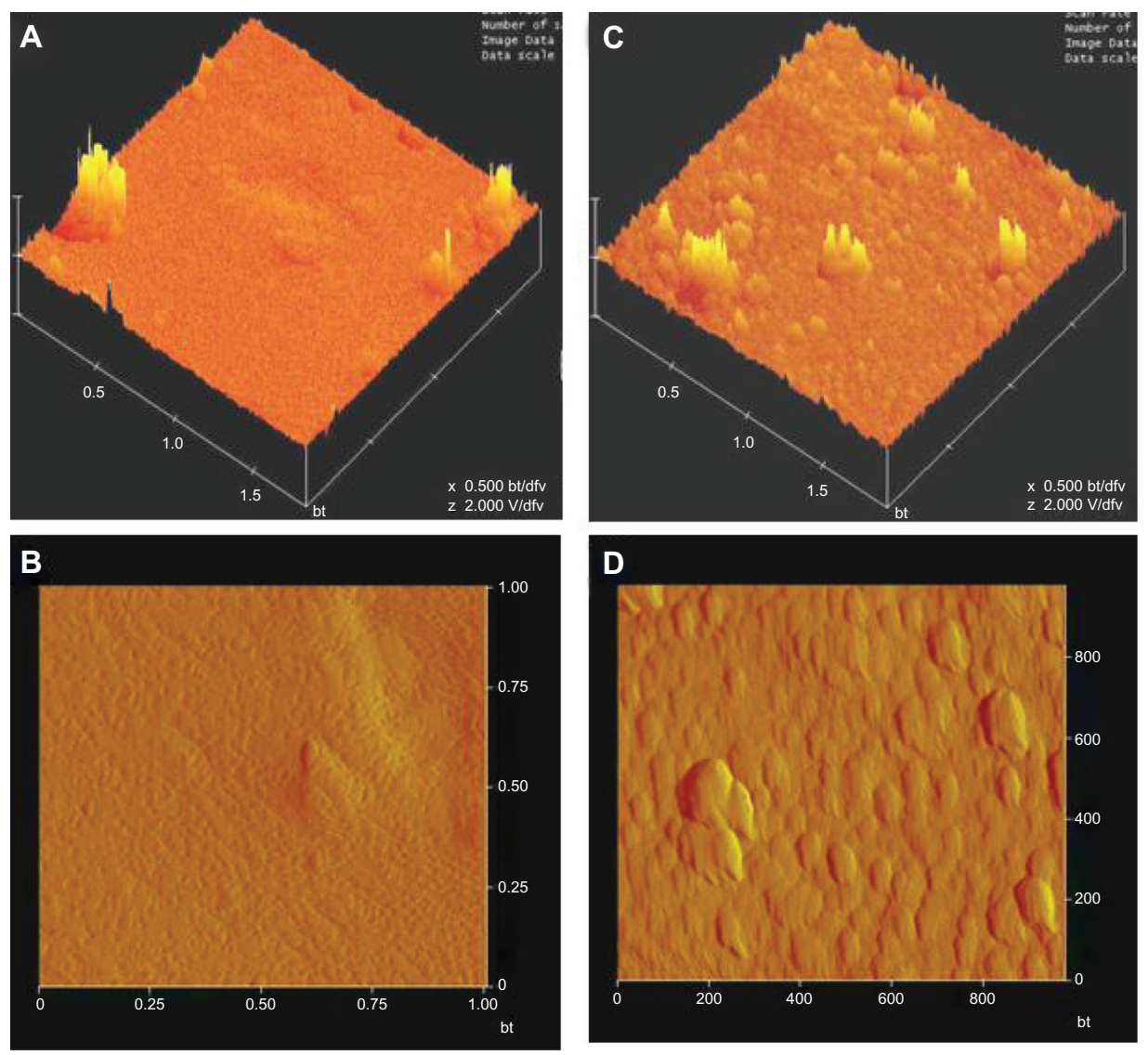

Figure 2 Atomic force microscope analysis for surface morphology of ( $\mathbf{A}$ and $\mathbf{B})$ bare and $(\mathbf{C}$ and $\mathbf{D})$ polyallylamine bisphosphonate-modified $3 \mathrm{I} 6 \mathrm{~L}$ steel.

as determined by Coomassie Brilliant Blue G-250. The results show that the amount of ${ }^{125}$ I-antibody chemically linked on the PAA-BP-modified stents was 17-fold higher than on the physically adsorbed control stents (Figure 3A; $P<0.01$ ). The chemically linked ${ }^{125} \mathrm{I}$-antibody showed a sustained release over a course of 21 days and approximately $50 \%$ of the total bound antibody was retained on the stents at the end of 21 days. However, the physically adsorbed antibody on the control stents was almost completely eluted out within 3 days (Figure 3B).

There was no significant difference in the binding capacity of ${ }^{125}$ I-antibody chemically linked on the PAABPP-modified stents (about $0.68 \mu \mathrm{g}$ ) and the collagencoated stents (about $0.76 \mu \mathrm{g}$ ) previously studied by the authors' group, in which anti-DNA antibody was covalently immobilized on the collagen-coated stents in the same way as the PAA-BP-modified stents. ${ }^{19}$ The antibody released from collagen-coated stents was relatively faster than the PAA-BP-modified stents, which shows that only $25 \%$ of the total bound antibody was retained on the collagen-coated stents at the end of 16 days. The results indicate that the method of PAA-BP-modified stents was superior to the collagen-coated stents in the binding stability of the antibody.

\section{Anchoring of rhodamine-labeled DAC micelles on PAA-BP-modified stents}

DAC micelles were successfully immobilized onto PAA-BPmodified stents as demonstrated by immunofluorescence studies using rhodamine-labeled DNA; control stents that did not contain sulfhydryl-linked anti-DNA antibody demonstrated faint autofluorescence (Figure 4). The result confirmed specific anchoring of micelles on SPDP-activated PAA-BP-modified stents. Further inspection of Figure 4A revealed that the anchoring of DAC micelles was generally uniform and devoid of large-scale patches of defects. It was previously reported that plasmid DNA/polyethyleneimine polyplexes nonspecifically adsorbed on hydrophobic surfaces were highly aggregated, resulting in reduced gene transfection efficiency. ${ }^{22,23}$ In the current study, the chemically linked DAC micelles were less aggregated and better distributed on the surface of PAA-BPmodified stent, which would increase the chance of being 
A

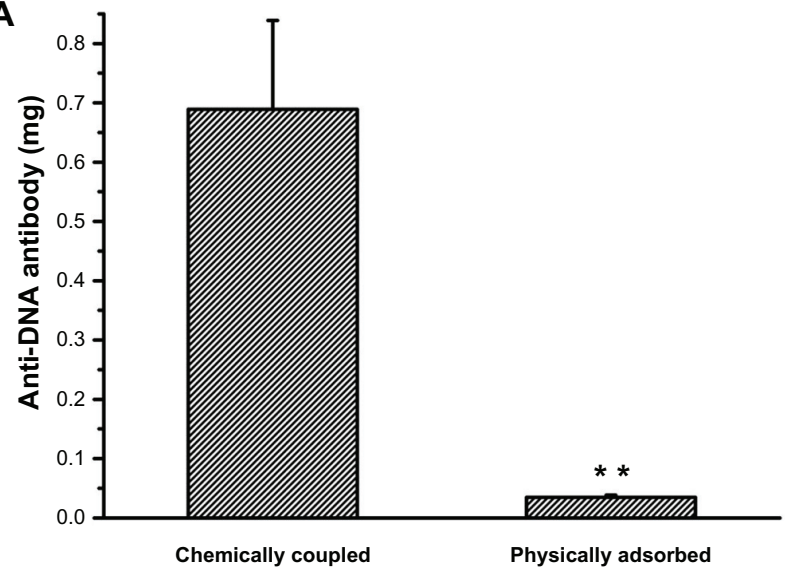

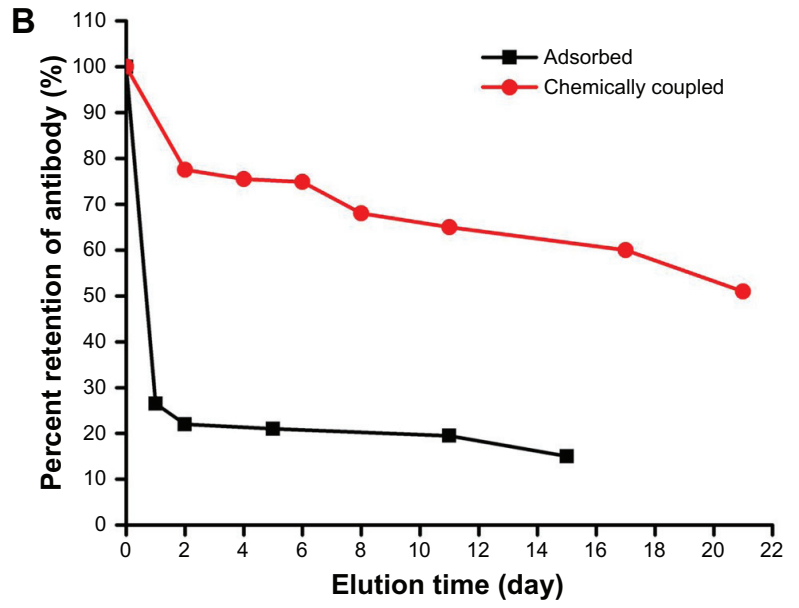

Figure 3 Binding capacity and stability of ${ }^{125}$-labeled anti-DNA antibody on the PAA-BP-modified stents. (A) The amount of antibodies chemically linked on stents was 19 -fold higher than on the physically adsorbed control stents $(* * P<0.0 \mathrm{I})$. (B) The chemically linked ${ }^{125}$-labeled anti-DNA antibody showed a sustained release over the course of $2 \mathrm{I}$ days and $50 \%$ of the total bound antibodies were retained on the stents by the end of $2 \mathrm{I}$ days. However, physically adsorbed antibody on the control stents was almost completely eluted out within 3 days.

transported within adhered cells through substrate-mediated gene transfection.

\section{In vitro gene transfection mediated by DAC micelle-tethered stents}

The PAA-BP-modified stents deposited with DAC micelles demonstrated efficient GFP gene transfection in A10 cells. The stents retrieved from cell culture after 72 hours of incubation contained numerous GFP-transfected cells that infiltrated the PAA-BP coating on the stents, indicating a highly localized and efficient gene delivery pattern (Figure 5A). However, on the control stents that had been immobilized with nonspecific antibody and incubated with the same amount $p E G F P-N 3$, only a few transfected GFP-positive cells were found (Figure 5B). Moreover, the stents showed no detrimental effects on cell growth.

The authors' group has focused on covalent linking of DAC micelles on the collagen-coated stents in order to deliver the plasmid DNA by a vector tethering mechanism. ${ }^{19,20}$
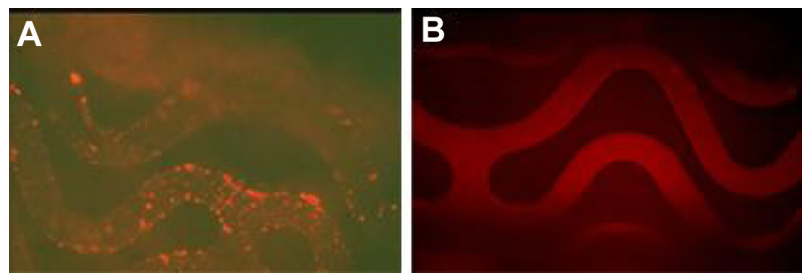

Figure 4 Representative fluorescence microscopy images of immobilization of rhodamine-labeled DNA/anti-DNA antibody/cationic lipid micelles on polyallylamine bisphosphonate-modified stents. (A) Chemically linked on the stents; (B) physically adsorbed on the control stents (fluorescein isothiocyanate, $\times 100$ ).
This approach has been shown to be feasible, with high levels of regional expression and no detectable spreading of the vector beyond the implanted artery. However, polymer-coated gene delivery stents is problematic because of harmful properties of the polymer coatings. ${ }^{8,9}$ Therefore, in the current study, DAC micelles were directly immobilized onto the surface of PAA-BP-modified stents without the use of a polymer coating. In vitro transfection data showed that DAC micelles linked on PAA-BP-modified stents by chemical and immunoreaction ensured highly localized and efficient gene transfection. This is simply because surface-immobilized DAC micelles have more chance of being in close proximity or in contact with cells, which can lead to high and long-lasting gene expression by immediate internalization and sustained release effects. ${ }^{24,25}$ In addition, the formation of nanoscale micelles can be crucial for cellular internalization of DNA and subsequent trafficking within cells. ${ }^{22,26}$
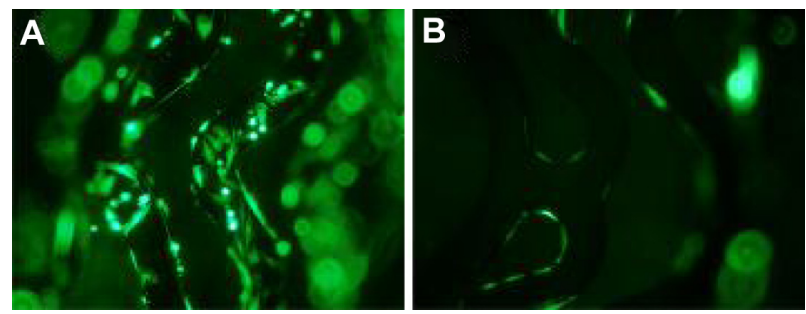

Figure 5 In vitro gene transfection mediated by pEGFP-N3/anti-DNA antibody/ cationic lipid micelles-tethered stents in AIO cells. (A) Positive transfection using pEGFP-N3/anti-DNA antibody/cationic lipid micelles modified stent (fluorescein isothiocyanate, $\times 100$ ); (B) negative control stents with a nonspecific anti-DNA antibody modification (fluorescein isothiocyanate, $\times 100$ ). 


\section{Conclusion}

Through surface modification with PAA-BP and subsequent anchoring of DAC micelles, functionalized stents with PAA-BP and DNA were created for cardiovascular gene delivery. The DAC micelle-immobilized PAA-BP-modified stents were successful as a gene delivery system, giving rise to efficient and localized gene delivery to arterial smooth muscle cells. Gene delivery using DAC micelle-tethered stent-based PAA-BP functionalization should be suitable for a wide array of single or multiple therapeutic gene strategies, and could be used on cardiovascular metallic implants for achieving efficient gene therapy.

\section{Acknowledgments}

The financial support of the projects was from the NSFC of China (50830106, 50903093, and 81271706).

\section{Disclosure}

The authors report no conflicts of interest in this work.

\section{References}

1. Sharif F, Daly K, Crowley J, O'Brien T. Current status of catheter- and stent-based gene therapy. Cardiovasc Res. 2004;64(2):208-216.

2. Gaffney MM, Hynes SO, Barry F, O’Brien T. Cardiovascular gene therapy: current status and therapeutic potential. Br J Pharmacol. 2007; 152(2):175-188.

3. Fishbein I, Stachelek SJ, Connolly JM, Wilensky RL, Alferiev I, Levy RJ. Site specific gene delivery in the cardiovascular system. $J$ Control Release. 2005;109(1-3):37-48.

4. Robertson KE, McDonald RA, Oldroyd KG, Nicklin SA, Baker AH. Prevention of coronary in-stent restenosis and vein graft failure: does vascular gene therapy have a role? Pharmacol Ther. 2012;136(1):23-34.

5. Sharif F, Hynes SO, Cooney R, et al. Gene-eluting stents: adenovirusmediated delivery of eNOS to the blood vessel wall accelerates reendothelialization and inhibits restenosis. Mol Ther. 2008;16(10): 1674-1680.

6. Che HL, Bae IH, Lim KS, et al. Suppression of post-angioplasty restenosis with an Akt1 siRNA-embedded coronary stent in a rabbit model. Biomaterials. 2012;33(33):8548-8556.

7. Egashira K, Nakano K, Ohtani K, et al. Local delivery of anti-monocyte chemoattractant protein-1 by gene-eluting stents attenuates in-stent stenosis in rabbits and monkeys. Arterioscler Thromb Vasc Biol. 2007; 27(12):2563-2568.

8. Carter AJ, Aggarwal M, Kopia GA, et al. Long-term effects of polymerbased, slow-release, sirolimus-eluting stents in a porcine coronary model Cardiovasc Res. 2004;63(4):617-624
9. Tesfamariam B. Local vascular toxicokinetics of stent-based drug delivery. Toxicol Lett. 2007;168(2):93-102.

10. Fishbein I, Alferiev I, Bakay M, et al. Local delivery of gene vectors from bare-metal stents by use of a biodegradable synthetic complex inhibits in-stent restenosis in rat carotid arteries. Circulation. 2008; 117(16):2096-2103.

11. Fishbein I, Alferiev IS, Nyanguile O, et al. Bisphosphonate-mediated gene vector delivery from the metal surfaces of stents. Proc Natl Acad Sci US A. 2006;103(1):159-164.

12. Queffelec C, Petit M, Janvier P, Knight DA, Bujoli B. Surface modification using phosphonic acids and esters. Chem Rev. 2012; 112(7):3777-3807.

13. Van Alsten JG. Self-assembled monolayers on engineering metals: structure, derivatization, and utility. Langmuir. 1999;15(22):7605-7614

14. Giacca M, Zacchigna S. Virus-mediated gene delivery for human gene therapy. J Control Release. 2012;161(2):377-388.

15. Elsabahy M, Nazarali A, Foldvari M. Non-viral nucleic acid delivery: key challenges and future directions. Curr Drug Deliv. 2011;8(3): 235-244.

16. Zhu L, Mahato RI. Lipid and polymeric carrier-mediated nucleic acid delivery. Expert Opin Drug Deliv. 2010;7(10):1209-1226.

17. Burton DY, Song CX, Fishbein I, et al. The incorporation of an ion channel gene mutation associated with the long QT syndrome (Q9E-hMiRP1) in a plasmid vector for site-specific arrhythmia gene therapy: in vitro and in vivo feasibility studies. Hum Gene Ther 2003;14(9):907-922.

18. Song CX, Zhang LH, Zhang C, Levy RJ. Study on a novel non-virus triplex gene vectors composed of plasmid DNA. Prog Biochem Biophys. 2007;34(8):830-835.

19. Jin X, Mei L, Song CX, et al. Immobilization of plasmid DNA on an anti-DNA antibody modified coronary stent for intravascular sitespecific gene therapy. J Gene Med. 2008;10(4):421-429.

20. Zhang LH, Luo T, Zhang C, et al. Anti-DNA antibody modified coronary stent for plasmid gene delivery: results obtained from a porcine coronary stent model. J Gene Med. 2011;13(1):37-45.

21. Hussain AA, Awad R, Crooks PA, Dittert LW. Chloramine-T in radiolabeling techniques. I. Kinetics and mechanism of the reaction between chloramine-T and amino acids. Anal Biochem. 1993;214(2):495-499.

22. Segura T, Shea LD. Surface-tethered DNA complexes for enhanced gene delivery. Bioconjugate Chem. 2002;13(3):621-629.

23. Kim TG, Lee Y, Park TG. Controlled gene-eluting metal stent fabricated by bio-inspired surface modification with hyaluronic acid and deposition of DNA/PEI polyplexes. Int J Pharm. 2010;384(1-2):181-188.

24. Luo D, Saltzman WM. Enhancement of transfection by physical concentration of DNA at the cell surface. Nat Biotechnol. 2000;18(8): 893-895.

25. Shen H, Tan J, Saltzman WM. Surface-mediated gene transfer from nanocomposites of controlled texture. Nat Mater. 2004;3(8):569-574.

26. Jiang JH, Bengali Z, Houchin TL, Shea LD. Surface adsorption of DNA to tissue engineering scaffolds for efficient gene delivery. $J$ Biomed Mater Res. 2006;77(1):50-58.
International Journal of Nanomedicine

\section{Publish your work in this journal}

The International Journal of Nanomedicine is an international, peerreviewed journal focusing on the application of nanotechnology in diagnostics, therapeutics, and drug delivery systems throughou the biomedical field. This journal is indexed on PubMed Central,

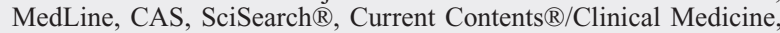

\section{Dovepress}

Journal Citation Reports/Science Edition, EMBase, Scopus and the Elsevier Bibliographic databases. The manuscript management system is completely online and includes a very quick and fair peer-review system, which is all easy to use. Visit http://www.dovepress.com/ testimonials.php to read real quotes from published authors. 